\title{
COMPARISON OF DURATION OF LABOUR BETWEEN PRIMIGRAVIDAS WITH AND WITHOUT AMNIOTOMY
}

\author{
NAZIA LIAQAT, SAADIAYASMEEN, FARHAT NASIR, REHANA RAHIM. \\ Department of Gynaecology and Obstetrics, PGMI, Lady Reading Hospital, Peshawar
}

\begin{abstract}
BACKGROUND: Amniotomy is a common and routine obstetrical procedure in many labour wards. It is mostly performed with the intention of accelerating the process of labour. The procedure is not risk free and the results of various studies performed on the subject are diverse. The rationale of this study was to obtain conclusive evidence on the effect of amniotomy on the duration of labour and to establish protocols for labour wards in the light of that evidence.

OBJECTIVES: To compare the duration of labour between primigravidas with and without amniotomy.

METHODOLOGY: The total number of patients was 50 in each group; A and B who were subjected to amniotomy and no amniotomy respectively. Duration of First and Second stage of labour were noted and Student T- test was applied to find the significance of difference in the duration of First and Second stages of labour of the two groups. Data was analyzed using SPSS version 17.0.

Results:: The mean ages of patients in Group A and B were 22.6 2.66 and $23 \pm 2.03$ years respectively (p value 0.647 ). The mean duration of gestation of Group A was $38.8 \pm 0.50$ weeks and of Group B was $39.16 \pm$ 0.52 weeks ( $p$ value 0.0634 ). The duration of First Stage was $169 \pm 77 \mathrm{~min}$ in Group A and $205 \pm 105$ minutes in Group B ( $p$ value 0.2877 ). The Second stage duration was $78.6 \pm 45$ in Group A and $72 \pm 32$ minutes in Group B ( $p$ value 0.6434).

CONCLUSION: Amniotomy has no significant effect in shortening the duration of labour in primigravidas.
\end{abstract}

KEYWORDS: Amniotomy, Primigravidas, Labour

\section{INTRODUCTION}

Amniotomy, is the artificial rupture of the amniotic membranes with the intention of accelerating the progress of labor, it is among the most commonly performed obstetrical procedures ${ }^{\prime}$. The primary aim of amniotomy is to speed up contractions and, therefore shorten the length of labor ${ }^{2}$.

Amniotomy is also a component of active management of labour. Active management of labour reduces the length of active labour and hence caesarean section rate. Active management of labour is a package of care, which in addition to routine amniotomy, includes strict diagnosis of labour, oxytocin for slow progress and one to one support in labour. With all these components of active management of labour together, about $63 \%$ of primigravidas deliver within 6 hours and $98 \%$ within 12 hours of admission. The extent to which amniotomy alone shortens labour varies widely from study to study ${ }^{3}$.

Despite being a so much common obstetrical procedure and so routinely performed in laboring patients, controversaries still exist regarding the potential effect of amniotony alone in shortening labour. One study show that a policy of early amniotomy in spontaneous labour (not inductions) is associated with a mean \pm S.D decrease of $155 \pm$ 40 minutes in the duration of first stage of labour $(\mathrm{P}-0.001)^{1}$. While there are others which show that it alone has no significant role in reducing the length of labour ${ }^{2,4,5}$.

It was this confusion still prevailing around the subject of amniotomy, its impact in terms of reducing duration of labour, that made us to undertake this study. Because routine early amniotomy is associated with both benefits and risks $^{6}$.The rationale of the study was to determine 
its ultimate effect on the duration of labour. If it turns out to be effective, this would help us in adopting it routinely without any confusion, for shortening labours and thus helping the busy delivery units in terms of saving time, resources and improving patient care. However if it does not make a significant difference, its routine application should then be discouraged, to avoid patient's discomfort and other harms of the procedure like cord prolapsed, placental abruption and infection ${ }^{7,8}$.

\section{METHODOLOGY}

It was a randomized control trial, conducted from $15^{\text {th }} \mathrm{Feb}, 2011$ to $15^{\text {th }} \mathrm{Dec}, 2011$, in the labour room of Gynae $\mathrm{C}$ unit of postgraduate medical institute, Lady Reading Hospital, Peshawar. Ethical clearance was obtained from the ethical committee of the hospital. It was non probability purposive sampling. Total number of patients included in the study was 100 , equally divided into two groups i.e Group A and Group B. Informed consents were taken from all the patients included in the study.

Primigravidas with uncomplicated Term gestation in whom labour had started spontaneously and having intact membranes and cervix $3-5 \mathrm{~cm}$ dilated were included in the study. Patients with multiple pregnancies, with abnormal fetal heart pattern, with presentation other than vertex and also with suspicion of having inadequate pelvis were excluded to control confounding variables. Patients requiring high dependency intrapartum care were also excluded as labour is actively managed in these patients to expedite delivery.

Patients were randomized to Amniotomy group (Group A) or control group (Group B), when they presented with a cervical dilatation, more than 3 $\mathrm{cm}$ or less than $5 \mathrm{~cm}$ after experiencing painful uterine contractions every 5 minutes for at least 1 hour. Randomization was done by toss of coin. Each patient was interviewed and examined by senior colleagues. Women in the amniotomy group underwent the procedure while those in the control group were tried to have the membranes conserved. Time of amniotomy was recorded.

Labour was not augmented with oxytocin. While performing amniotomy, the woman was advised to empty her bladder spontaneously and then put in lithotomy position. Parts cleaned and drapped. During cervical examination, Bishop Score was assessed, the inferior pole of the membranes ruptured by the Kocker forceps. The amount and color of liquor drained noticed and documented. FHR checked. All labours were recorded on partogram, with an alert line representing cervical dilatation of $1 \mathrm{~cm} /$ hour and an action line drawn four hours to the right of alert line. Access to analgesia was freely available in the form of 50$100 \mathrm{mg}$ Tramadol, intra muscular. All the assessments were made by a single person to remove the chance of inter observer bias. All the data was then collected on the preformed performas.

All the nominal variables like booking status, period of gestation, various modes of delivery and perinatal outcome were recorded and frequencies and percentages were calculated. Chi-square test was applied to determine the $p$ value and a $p$ value of less than 0.05 was considered significant.

Numerical variables like patient's age, body mass index, duration of first and second stages of labor were recorded and mean and standard deviation were calculated for each variable. Student T test was applied to determine the $p$ value. $P$ value of less than 0.05 was considered significant. All these calculations were done using SPSS version 17.

\section{RESULTS}

The total number of patients was 50 in each group; $A$ and $B$ with and without amniotomy respectively. The mean age of patients in Group A was $22.6 \pm$ 2.66 years and in Group B was $23.00 \pm 2.03$ years $(p=0.647)$.

In Group A 20\% $(n=10)$ were booked patients of the unit and in Group B 53\% $(n=26)$ were booked cases $(p=0.128)$ (Graph N0.1) The body mass index of patients in Group A and B was $26.40 \pm$ 2.55 and $26.73 \pm 2.08 \mathrm{~kg} / \mathrm{m}^{2}$ respectively $(\mathrm{p}=0.7007)$.

The mean duration of gestation of patients in Group A was 38.8 \pm 0.50 weeks and in Group B was $39.16 \pm 0.52$ weeks. $(p=0.0634)$. 
The duration of labour from the time of randomization till full cervical dilatation (stage I) was 169.00 minutes $\pm 77.57 \mathrm{SD}$ in the Group A while in Group B, it was 205.66 minutes \pm 105.57SD with insignificant $p$ value of 0.28 .

The duration of labour from full cervical dilatation till delivery (Stage II) was 78.67 minutes \pm 44.857SD in Group A and in Group B, it was 72.00 minutes $\pm 32.17 \mathrm{SD}$ with insignificant $\mathrm{p}$ value of 0.6434 .

TABLE No.1:

Demographic features of the two groups

\begin{tabular}{|c|c|c|c|}
\hline & $\begin{array}{c}\text { GROUP A } \\
(\mathrm{n}=50)\end{array}$ & $\begin{array}{c}\text { GROUP } \mathrm{B} \\
(\mathrm{n}=\mathbf{5 0})\end{array}$ & P-VALUE \\
\hline AGE & $22.6 \pm 2.66$ & $\ldots$ & $\mathrm{p}=0.647$ \\
\hline BOOKING STATUS & $20 \%(\mathrm{n}=10)$ & $53 \%(\mathrm{n}=26)$ & $\mathrm{p}=0.128$ \\
\hline BODY MASS INDEX & $26.40 \pm 2.55$ & $26.73 \pm 2.08$ & $\mathrm{p}=0.7007$ \\
\hline PERIOD OF GESTATION & $38.8 \pm 0.50$ & $39.16 \pm 0.52$ & $\mathrm{p}=0.0634$ \\
\hline
\end{tabular}

DURATION OF FIRST STAGE AND SECOND STAGE OF LABOR (MINUTES) IN PATIENTS IN GROUP A (WITH AMNIOTOMY) AND GROUP B (WITH OUTAMNIOTOMY)

\begin{tabular}{|c|c|c|c|}
\hline & GROUPA & GROUP B & P-VALUE \\
\hline $\begin{array}{c}\text { DURATION OF FIRST } \\
\text { STAGE }\end{array}$ & $169.00 \pm 77.57$ & $205.66 \pm 105.57$ & 0.28 \\
\hline $\begin{array}{c}\text { DURATION OF SECOND } \\
\text { STAGE }\end{array}$ & $78.67 \pm 44.857$ & $72.00 \pm 32.17$ & 0.6434 \\
\hline
\end{tabular}

\section{DISCUSSION}

Intentional artificial rupture of the amniotic membranes during labour, sometimes called amniotomy or "breaking of the waters," is one of the most commonly performed procedures in modern obstetric and midwifery practice.

In our study the duration of First stage was 169.00 minutes $\pm 77.57 \mathrm{SD}$ in the amniotomy group while in control group, it was 205.66 minutes \pm 105.57SD. But statistically this difference in duration was insignificant ( $p$ value 0.28 ). However, this outcome may be influenced by the differences between the inclusion criteria pertaining to the frequency and strength of uterine contractions. For example, there may be a shorter time interval between women randomized with contractions of 3 or more in 10 minutes and each lasting for more than 20 seconds, which is not accounted for in the analysis. It is difficult to make recommendations for this reason. Also the duration Second Stage was 78.67 minutes \pm 44.857SD in amniotomy group and in control group, it was 72.00 minutes $\pm 32.17 \mathrm{SD}$ with $\mathrm{p}$ value of 0.6434 . There was no significant difference in the length of second stage of labour between the two groups. On the basis of these results the routine use of amniotomy is unlikely to be of clinical significance and probably is not justified.

There were several findings which were not statistically significant. There were no differences between the two groups in terms of mean age $(p=0.647)$, booking status for delivery in hospital $(p=0.128)$, body mass index $(p=0.7007)$, duration of gestation $(p=0.0634)$.

Several studies have been done for the effects of amniotomy on the duration of labor. All research work done in past on the subject show contradictory results. Some have advocated its use with significance difference while others are not recommending it. But there is overwhelming consensus regarding the safety of procedure.

In a local study by Abdullah A et al, ${ }^{9}$ the efficacy of amniotomy with spontaneous rupture of membranes was compared in terms of progress of labour, mode of delivery and fetal outcome in 200 primigravidae. This study showed that artificially rupturing the membranes during active labour in primigravidae significantly decreased the duration of labour while there was no significant difference in terms of mode of delivery and fetal outcome between the two groups.

But on the other hand Smyth Rm et al, ${ }^{2}$ did a review of 14 studies involving 4893 women and on the basis of this review; amniotomy was not recommended to be introduced routinely as part of standard labour management and care.

In this review by Smyth $\mathrm{Rm}$ ET $\mathrm{al}^{2}$, five trials studied the effect of amniotomy on the duration of First stage of labour there after. There was no statistically significant reduction in the length of first stage of labour whether be in primiparous or multifarious women. 
Seven trials of the same review reported the outcome of length of second stage of labour withamniotomy and these too showed no statistically significant difference in the length of second stage of labour between amniotomy and no amniotomy groups.

Friedman and Sachtleben ${ }^{10}$ and SS Ratnam ${ }^{11}$ could also demonstrate no significant effect of amniotomy alone on the duration of labour. In the latter study it was shown that the labour was shortest when spontaneous rupture of membranes occurred early in labour and longest when the membranes were artificially ruptured after the labour was established. It was also observed in the study that amniotomy in labour at any stage of cervical dilatation had no visible effect in shortening the overall duration of labour.

This shortening of labour with spontaneous rupture of membranes was attributed to natural selection resulting from either a greater uterine motility or a prelab our cervical dilatation or both.

From these observations it can be concluded that if the aim is to shorten labour then artificial rupture of the membranes in established labour fails to fulfil that aim.Its routine use for this purpose is therefore not justified. However, in cases of prolonged first stage of labour due to uterine inertia, time lyamniotomy followed, if necessary by oxytocin is likely to result in acceleration of labour.

Amniotomy also permits examination of the quantity and quality of the liquor amnii, especially in cases of suspected placental insufficiency and fetal distress. This latter advantage have practical values which are known to every obstetrician and requires no large scale controlled studies to verify. Thus amniotomy as a routine procedure in labour does not shorten labour but the procedure is relatively safe and can be carried out when there is an indication such as uterine inertia, suspected placental insufficiency or fetal distress.

The risks of amniotomy can be minimized by careful selection, excluding those not in labour and those with unengaged fetal heads.

\section{CONCLUSION \& RECOMMENDATIONS}

From the results of our study, it has been concluded that "There was no statically significant difference in the duration of labor in amniotomy and without amniotomy groups. So amniotomy has no important effect on the duration of labour in primigravidas and thus the artificial rupture of membranes alone for the purpose of shortening the duration of labour is not recommended."

\section{REFERENCES}

1. Shobeir F, Tehranian N, Nazari M. Amniotomy in labour. Int J GynecolObstet 2007;96:197-8.

2. Smyth RM, Alldred SK, Markham C. Amniotomy for shortening spontaneous labour. Cochrane Database Syst Rev 2007:CD006167.

3. Pates JA, Satin AJ. Active management of labour. Obstet GynaecolClin NAm 2005;32:221-30.

4. Ajadi MA, Kuti O, Orji EO, Ogunnivi SO, Sule SS. The effect of amniotomy on the outcome of spontaneous labor in uncomplicated pregnancy. J ObstetGynaecol 2006;26:631-4.

5. Calder AA. Normal labour. In: Edmonds DK, editors. Dewhursts text book of obstetrics and gynaecology. India: Blackwell publishing; 2007. p. 53.

6. HC Brown, S Paranjothy, T Dowsell, J Thomas. Package of care for active management in labour for reducing caesarean section rates in low-risk women. ObstetGynaecol 2009;113:218-20.

7. Fraser WD, Turcot L, Krauss I, Brisson-Carrol G. Amniotomy for shortening spontaneous labour (Cochrane Review). In: The Cochrane Library,1,200. Oxford: Update Software.

8. American College of Obstetricians and Gynaecologists Committee on Practice Bulletins-Obstetrics.ACOG Practice Bulletin. Dystocia and augmentation of labour. Obstet Gynecology 2003;102:1445-54.

9. Abdullah A, Saboohi S, Hashami U. Effects of amniotomy versus spontaneous rupture of membrane on progress of labour and fetal outcome in primigravidae. JLUMHS 2010Jan-Apr; 09( 01):3336.

10. Friedman E.A, Sachtleben M.R. Amniotomy. Obstetrics Gynaecology 1963;22(6):755.

11. Ratnam S.S, Tow S.H. Amniotomy in labour. Singapore Medical Journal 1969 Mar;10(1):50-3.

\section{FOR CORRESPONDENCE:}

Dr. Nazia Liaqat

Department Of Gynecology and Obstetrics, PGMI, Lady Reading Hospital Peshawar.

Cell \#:03339487717

Email:dr_nazialiaqat@yahoo.com 